\title{
One-dimensional imidazole aggregate in aluminium porous coordination polymers with high proton conductivity
}

\section{$\operatorname{AUTHOR}(S)$ :}

Bureekaew, Sareeya; Horike, Satoshi; Higuchi, Masakazu; Mizuno, Motohiro; Kawamura, Takashi; Tanaka, Daisuke; Yanai, Nobuhiro; Kitagawa, Susumu

\section{CITATION:}

Bureekaew, Sareeya ...[et al]. One-dimensional imidazole aggregate in aluminium porous coordination polymers with high proton conductivity. Nature Materials 2009, 8: 831-836

\section{ISSUE DATE:}

2009-10

URL:

http://hdl.handle.net/2433/85349

\section{RIGHT:}

c 2009 Nature Publishing Group All Rights Reserved. 許諾条件により本 文は2010-03-06に公開.; This is not the published version. Please cite only the published version.; この論文は出版社版でありません。引用の 際には出版社版をご確認ご利用ください。 


\section{One-Dimensional Imidazole Aggregate in Aluminum Porous}

\section{Coordination Polymers with High Proton Conductivity}

5

8

9

10

11

12

13

14

15

16

17

18
Sareeya Bureekaew ${ }^{1,5}$, Satoshi Horike ${ }^{1,5}$, Masakazu Higuchi ${ }^{2}$, Motohiro Mizuno $^{3}$, Takashi Kawamura ${ }^{1}$, Daisuke Tanaka ${ }^{1}$, Nobuhiro Yanai ${ }^{1}$, Susumu Kitagawa ${ }^{1,4,5}$

(1) Department of Synthetic Chemistry and Biological Chemistry, Graduate School of Engineering, Kyoto University, Katsura, Nishikyo-ku, Kyoto 615-8510, Japan,

(2) RIKEN, SPring-8 center, 1-1-1, Kouto, Sayo-cho, Sayo-gun, Hyogo 679-5148, Japan

(3) Department of Chemistry, Graduate School of Natural Science and Technology, Kanazawa University, Kanazawa 920-1192, Japan

(4) Institute for Integrated Cell-Material Sciences (iCeMS) Kyoto University, Yoshida, Sakyo-ku, Kyoto 606-850, Japan,

(5) Kitagawa Integrated Pore Project, Exploratory Research for Advanced Technology (ERATO), Japan Science and Technology Agency (JST), Kyoto Research Park, 134 Chudoji Minami-machi, Shimogyo-ku, Kyoto 600-8813, Japan

\section{CORRESPONDING AUTHOR FOOTNOTE}

Dr. Susumu Kitagawa

Department of Synthetic Chemistry and Biological Chemistry, Graduate School of Engineering, Kyoto University Katsura, Nishikyo-ku, Kyoto 615-8510, Japan

TEL: +81-75-383-2833

FAX: +81-75-383-2732

e-mail: kitagawa@sbchem.kyoto-u.ac.jp 
1 ABSTRACT: The development of anhydrous proton-conductive materials operating at temperatures

2 above $80{ }^{\circ} \mathrm{C}$ is a challenge that needs to be met for practical applications. Herein, we propose the new

3 idea of encapsulation of a proton-carrier molecule-imidazole in this work-in aluminum porous

4 coordination polymers for the creation of a hybridized proton conductor under anhydrous conditions.

5 Tuning of the host-guest interaction can generate a good proton-conducting path at temperatures above

$6100{ }^{\circ} \mathrm{C}$. The dynamics of the adsorbed imidazole strongly affect the conductivity determined by ${ }^{2} \mathrm{H}$

7 solid-state NMR. Isotope measurements of conductivity using imidazole- $d_{4}$ showed that the

8 proton-hopping mechanism was dominant for the conducting path. This work suggests that the

9 combination of guest molecule and a variety of microporous frameworks would afford highly mobile

10 proton carriers in solids and gives an idea for designing a new type of proton conductor, particularly

11 for high temperature and anhydrous conditions.

13 KEYWORDS: porous coordination polymer, metal-organic framework, proton conductivity, 14 solid-state NMR

15

Anhydrous proton-conducting solids that are able to operate at high temperature $\left(\sim 120{ }^{\circ} \mathrm{C}\right)$ are required in fuel cell technology. ${ }^{1,2}$ Heterocyclic organic molecules such as imidazole or benzyl imidazole have attracted considerable attention for this purpose because they are nonvolatile molecules with high boiling points, and they can exist in two tautomeric forms with respect to a proton that moves between the two nitrogen atoms, which supports a proton transport pathway. ${ }^{3,4}$ The protonic defect may cause local disorder by forming protonated and unprotonated imidazoles. In such materials the proton transport may occur through structure diffusion which involves proton transfer between the imidazole and the imidazolium ion through the hydrogen-bonded chain, including the molecular reorientation process for subsequent intermolecular proton transfer. ${ }^{1}$ Theoretically, the magnitude of the ionic conductivity is given as 


$$
\sigma(T)=\sum n_{i} q_{i} \mu_{i}
$$

2 where $n_{i}$ is the number of carriers, and $q_{i}$ and $\mu_{i}$ are the charge and mobility of the carriers,

3 respectively. ${ }^{5}$ Both a large amount and a high mobility of ion carriers are required to provide good 4 proton conductivity. Hence it is important to find suitable materials that meet these requirements. For

5 instance, solid imidazole has a low conductivity $\left(\sim 10^{-8} \mathrm{~S} \mathrm{~cm}^{-1}\right)$ at ambient temperature ${ }^{6}$ although the 6 imidazole density $\left(n_{i}\right)$ is adequately high. This is because the dense packing of imidazole, with strong 7 hydrogen bonding in the solid state, decreases the mobility of each molecule $\left(\mu_{i}\right)$.

8 The main goal of proton conductor modification should therefore be an improvement of the mobility 9 of proton carriers. It is known that local and translational motion of proton carriers strongly affect the 10 proton transfer rate. ${ }^{1}$ In order to control the mobility of proton carriers, additional support matrices such 11 as flexible organic polymers or high-porosity solids that afford movable space for a carrier are 12 considered promising.

13 Porous coordination polymers (PCPs) or metal organic frameworks constructed from transition 14 metal ions and organic ligands have received much attention over the past few years because of their 15 promising applications, such as in gas storage, ${ }^{7-11}$ separation, ${ }^{12-17}$ catalysis, ${ }^{18-26}$ and conductivity. ${ }^{27-29}$ 16 Recent developments in approaches to combine PCP frameworks and functional guests such as 17 polymers, ${ }^{30,31}$ metals,,$^{22,32-34}$ or small organic molecules ${ }^{35-37}$ on a molecular scale have prompted us to create hybrid materials with novel performance based on the feature that crystalline nanochannels can

19 afford a unique assembly field for functional guests with specific host-guest interactions. The guests in 20 the nanospace of PCPs exhibit unusual behavior compared to in the bulk phase because each manner of 21 assembly is heavily dependent on the nature of the PCP channels, such as their size, shape and chemical 22 environment. Hence, we propose the use of PCPs for incorporation with proton carrier molecules 23 because they can contribute to provide desirable working space for carrier molecules, with high mobility, 24 and show an appropriate packing structure, for improved proton conductivities at high temperatures and under anhydrous conditions (Figure 1). 
1 In this study we focused on two types of PCPs with 1D channels and high thermal stability ( $\sim 400$

$\left.2{ }^{\circ} \mathrm{C}\right)$, and imidazole as the guest proton carrier molecule. Taking the size and shape of imidazole $(4.3 \times$

$\left.3 \quad 3.7 \AA^{2}\right)$ into consideration, we chose to use the aluminum compounds $\left[\mathrm{Al}\left(\mu_{2}-\mathrm{OH}\right)(1,4 \text {-ndc })\right]_{n}(\mathbf{1} ; 1,4$-ndc

$4=1,4$-naphthalenedicarboxylate $)^{38} \quad$ and $\quad\left[\mathrm{Al}\left(\mu_{2}-\mathrm{OH}\right)(1,4 \text {-bdc })\right]_{n} \quad(2 ; \quad 1,4$-bdc $\quad=$

5 1,4-benzenedicarboxylate), ${ }^{9,39}$ both of which have pore dimensions of ca. $8 \AA$, but different pore shapes

6 and surface potential, and installed imidazole in each host material. We found that the nanochannels

7 potentiated the different packing of imidazole, compared with the bulk solid imidazole. Conductivity

8 measurements for each of the PCP-imidazole composites at various temperatures and under anhydrous

9 condition presented different profiles because of the different characteristics of the channels of the

10 respective PCPs, resulting in different host-guest interactions, and $\mathbf{1} \supset \mathrm{Im}$ had a conductivity of $2.2 \times$

$1110^{-5} \mathrm{~S} \mathrm{~cm}^{-1}$ at $120^{\circ} \mathrm{C}$. We investigated the behavior of absorbed imidazole in the micropores by means

12 of the solid-state NMR technique, and succeeded in determining a good correlation between the features

13 of the host channels, guest mobility and proton conductivity.

14 Structural information of 1 and 2

15 The structures of 1 and 2 comprise an infinite number of chains of corner-sharing $\mathrm{AlO}_{4}\left(\mu_{2}-\mathrm{OH}\right)_{2}$

16 interconnected by the dicarboxylate ligand, resulting in a 3D framework containing $1 \mathrm{D}$ channels. The

17 guest-free structures of $\mathbf{1}$ and $\mathbf{2}$ are shown in Figure 2. Crystallographic structures show that the pore

18 surfaces of $\mathbf{1}$ and $\mathbf{2}$ are composed of hydrophobic (aromatic naphthalene and benzene ring) and

19 hydrophilic $\left(\mathrm{AlO}_{4}\left(\mu_{2}-\mathrm{OH}\right)_{2}\right)$ parts. The principal difference between the two aluminum frameworks

20 arises from the difference in ligands 1,4-ndc and 1,4-bdc. Because of asymmetric bridging ligand, 1

21 consists of two kinds of rectangular channels with dimensions of $7.7 \times 7.7 \AA^{2}$ and $3.0 \times 3.0 \AA^{2}$ running

22 along the $c$ axis (Figure 2a). This compound shows the property of a rigid framework. Figure 2b shows

23 that steric hindrance arising from the bulky naphthalene ring of the 1,4-ndc ligand of 1 induces

24 restriction of interaction between the polar guest molecule and $\mu_{2}-\mathrm{OH}$ and/or carboxylate group of the

25 framework. Because of the absence of an accessible hydrophilic pore surface the hydrophobic character 
1 from the aromatic part of the naphthalene ring of the ligand is dominant. In other words, $\mathbf{1}$ provides two

2 types of microchannels with hydrophobic pore surfaces.

3 In the case of 2 the framework exhibits only 1D diamond-shaped channels composed of the smaller

4 benzene moieties of 1,4-bdc, with dimensions $8.5 \times 8.5 \AA^{2}$, running along the $a$ axis. Eventually, the

5 polar sites on the surface are exposed to guest molecules, which enhances guest-induced structural

6 transformation of 2 , with the aid of the interaction between the imidazoles and $\mu_{2}-\mathrm{OH}$ and/or a

7 carboxylate groups. ${ }^{40}$ Thus, it is intriguing that a simple modification on the organic moiety produces

8 channels with different nature, hydrophobic and hydrophilic for $\mathbf{1}$ and 2, respectively. ${ }^{39}$

\section{Properties of the inclusion compounds}

2つIm indicate the imidazole hybrid compound of $\mathbf{1}$ and 2, respectively. The existence of imidazole in $\mathbf{1}$

and 2, without any reactions/conversion, was confirmed by thermogravimetry/mass spectrometry

(TG-MS). The TG profile of $\mathbf{1} \supset \mathrm{Im}$ shows $14 \%$ weight imidazole loading or 0.6 imidazole/1 Al ion. The

release of accommodated imidazole commences at $160{ }^{\circ} \mathrm{C}$ and completes at $225{ }^{\circ} \mathrm{C}$. In the case of 2 , the

loaded imidazole amounts to $30 \%$ weight or 1.3 imidazole/ $1 \mathrm{Al}$ ion, which is twice as much as in $\mathbf{1}$. The

TG curve shows that the loss of imidazole molecules in 2つIm occurs in two steps: in the first step, the

release of imidazole commences at $130{ }^{\circ} \mathrm{C}$ and is completed by approximately $160{ }^{\circ} \mathrm{C}$ and in the second

step it commences at $160{ }^{\circ} \mathrm{C}$ and is completed by $240{ }^{\circ} \mathrm{C}$. The percentage imidazole loss is half the

amount of the imidazole, followed by the residual in the second step.

The one single step mass loss in $\mathbf{1} \supset \mathrm{Im}$ is indicative of uniformly accommodated imidazole

21 molecules. On the other hand, based on the TG curve of 2つIm, there are two types of imidazole molecules installed in the channel. According to the amphiphilic nature of the surface of the channel, the imidazoles with strong interaction with the hydrophilic sites of a $\mu_{2}-\mathrm{OH}$ or a carboxylate group are released at higher temperature $\left(160-240{ }^{\circ} \mathrm{C}\right)$, correlated to the weight loss in second step, whereas the 
1 The crystal structures of $\mathbf{1}$ and $\mathbf{2}$ (Figure 2) reveal the following. Compound $\mathbf{1}$ consists of two types

2 of $1 \mathrm{D}$ channels, namely small channels with dimensions $3.0 \times 3.0 \AA^{2}$ in which imidazole is unable to be

3 installed: only large channels with dimensions of $7.7 \times 7.7 \AA^{2}$ can install the guest. Compared with

$42 \supset \mathrm{Im}$, half the amount of accommodating imidazole per one $\mathrm{Al}$ is reasonable from crystal structures.

5 Considering that the dispersion of imidazole is uniform in the crystalline channel we could calculate

6 the density of imidazole in the larger channels of $1\left(443 \AA^{3}\right)$ and channels of $2\left(750 \AA^{3}\right)$. This was

7 calculated from the void space of the guest-free state by using the PLATON software package. ${ }^{41}$ The $^{2}$

8 values were about 0.15 and $0.19 \mathrm{~g} \mathrm{~cm}^{-3}$, respectively. However, as the structure of 2 changes after

9 accommodation of imidazole and it is difficult to determine the density of imidazole in $2 \supset$ Im. The

10 density of imidazoles in $\mathbf{1} \supset \mathrm{Im}$ and $\mathbf{2} \supset \mathrm{Im}$ are much smaller than that of solid bulk imidazole, which is

$11 \quad 1.23 \mathrm{~g} \mathrm{~cm}^{-3}$ at ambient temperature. ${ }^{42}$ This evidence indicates that the behaviors of imidazoles loaded to 12 the framework considerably differ from bulk imidazole resulting from the space effect.

13 The X-ray powder diffraction (XRPD) patterns shown in Figure 4 show that the diffraction pattern

14 of $\mathbf{1} \supset \mathrm{Im}$ is the same as that of apohost $\mathbf{1}$, corresponding to the robustness of $\mathbf{1}$. Conversely, the peak 15 positions and pattern of $\mathbf{2} \supset$ Im are different from those of apohost $\mathbf{2}$ and the shrinkage after installation

16 of imidazole is observed. This is because of strong interaction between the polar imidazole and hydrophilic pore surface of flexible 2 .

\section{Conductivity of 1 IIm and 2 JIm}

We aimed to achieve proton conductivity at temperatures around $100{ }^{\circ} \mathrm{C}$, and hence to design composites that are stable at the target temperatures. We already confirmed that the prepared composites

21 1 $\mathrm{Im}$ and $2 \supset \mathrm{Im}$ are stable up to $130{ }^{\circ} \mathrm{C}$ without any loss from TG. Conductivities of $1 \supset \mathrm{Im}$ and $2 \supset \mathrm{Im}$ were measured by AC impedance spectroscopy, which is a versatile electrochemical tool to characterize intrinsic electrical properties of materials. Figure $5 b$ and $5 c$ shows Nyquist plots $\left(Z^{\prime}\right.$ versus $\left.Z^{\prime}\right)$ of the

24 complex impedance measured on $\mathbf{1} \supset \mathrm{Im}$ and $2 \supset \mathrm{Im}$ under a nitrogen atmosphere at $120{ }^{\circ} \mathrm{C}$. The 25 impedance plots of the two complexes are typical of materials with predominant ionic conductivity. 
1 They show one semicircle with a characteristic spur at low frequencies, which indicates blocking of $\mathrm{H}^{+}$

2 ions at the gold electrodes. The magnitude of $Z^{\prime}$ decreased with an increase in temperature. The

3 conductivity of the samples was calculated from the impedance value using the following equation

$$
\sigma=\frac{L}{Z \cdot A}
$$

5 where $\sigma$ is the conductivity $\left(\mathrm{S} \mathrm{cm}^{-1}\right), L$ is the measured sample thickness $(\mathrm{cm}), A$ is the electrode area

$6 \quad\left(\mathrm{~cm}^{2}\right)$ and $Z$ is the impedance $(\Omega)$.

7 The temperature dependence of proton conductivities of $\mathbf{1}, \mathbf{1} \supset \mathrm{Im}$ and $2 \supset \mathrm{Im}$, measured under 8 anhydrous conditions at temperatures ranging from 25 to $120^{\circ} \mathrm{C}$, are shown in Figure 5 a. Guest-free $\mathbf{1}$

9 exhibits a conductivity lower than $10^{-13} \mathrm{~S} \mathrm{~cm}^{-1}$, confirmed by DC measurement, which is indicative of 10 negligible proton conductivity for this apohost framework. After installation of imidazole the proton 11 conductivity of $1 \supset \mathrm{Im}$ is $5.5 \times 10^{-8} \mathrm{~S} \mathrm{~cm}^{-1}$ at room temperature. Although the mole fraction of imidazole 12 in $\mathbf{1} \supset$ Im is much smaller than that of bulk imidazole, the proton conductivity of $\mathbf{1} \supset$ Im is of the same 13 order as that of solid bulk imidazole. This is possibly because of the effect of the nanospace on the 14 dynamic motion of imidazole. The proton conductivity of $\mathbf{1} \supset$ Im improves significantly as the 15 temperature increases: at $120{ }^{\circ} \mathrm{C}$ the proton conductivity reaches $2.2 \times 10^{-5} \mathrm{~S} \mathrm{~cm}^{-1}$. Note that bulk 16 imidazole at this temperature is no longer in the solid phase. This increase in the temperature dependent 17 conductivity of $\mathbf{1} \supset \mathrm{Im}$, compared with the conductivity profile of apohost $\mathbf{1}$, indicates that a significant 18 improvement in the conductivity arises directly from the accommodated imidazole. Furthermore, the 19 conductivity of $\mathbf{1} \supset$ Im continuously increases with an increase in temperature with the activation energy 20 of $0.6 \mathrm{eV}$. This result indicates that phase transition does not take place. The mobile imidazole induces 21 high temperature $\left(>100^{\circ} \mathrm{C}\right)$ proton conductivity in $\mathbf{1} \supset \mathrm{Im}$. We can improve the mobility of imidazole by 22 taking advantage of the isolating effect of PCPs. As the evidence from isotope effect (Figure S1), the 23 proton conductivity of our systems is mainly contributed by proton hopping mechanism. 
1 In order to improve proton conductivity we increased the amount of loaded imidazole (the number

2 of charge carriers, $n_{i}$ ) by using 2 , which has twice the amount of accessible space for imidazole as the

3 supporting framework. However, the proton conductivity of $2 \supset \mathrm{Im}$ at ambient temperature is about $10^{-10}$

$4 \mathrm{~S} \mathrm{~cm}^{-1}$, which is lower than that of $\mathbf{1} \supset \mathrm{Im}$. As in the case of $\mathbf{1} \supset \mathrm{Im}$, the conductivity of $2 \supset \mathrm{Im}$ increases as

5 the temperature increases with the activation energy of $0.9 \mathrm{eV}$, and it reaches $1.0 \times 10^{-7} \mathrm{~S} \mathrm{~cm}^{-1}$ at 120

$6{ }^{\circ} \mathrm{C}$. The proton conductivity of $\mathbf{2} \supset \mathrm{Im}$ is about two orders of magnitude lower than that of $1 \supset \mathrm{Im}$,

7 although the amount of loaded imidazole is higher than that of $\mathbf{1} \supset \mathrm{Im}$. This is also possibly because of

8 the difference in dynamic motion of the guest, which is based on the interaction between guest and host.

9 Microchannels in compound $\mathbf{1}$ have nonpolar potential surface and polar imidazole does not interact

10 strongly with the host framework; therefore, it can move freely in this channel. Nonetheless, in the case

11 of polar surface microchannels in 2 , the half amount of imidazole interact strongly with the hydrophilic

12 sites of host framework. The strong host-guest interactions give rise to the shrinkage of the framework,

13 eventually of a unit cell, resulting in the different environment of imidazole accommodated in 2,

14 compared to in $\mathbf{1}$. Therefore, because of strong host-guest interaction and dense packing, the imidazoles

15 with strong interaction with the $\mu_{2}-\mathrm{OH}$ and/or carboxylate group of 2 are not allowed to move or rotate

16 freely in the framework. Consequently, the conductivity in $\mathbf{1} \supset \mathrm{Im}$ is larger than in $\mathbf{2} \supset \mathrm{Im}$.

17 Direct observation of dynamics of imidazoles in 1دIm and in 2دIm

18 Solid-state ${ }^{2} \mathrm{H}$ NMR spectroscopy is suitable for examining the dynamics of target molecules

19 selectively. ${ }^{43-45}$ We therefore used this analytical technique to determine the mobility and its correlation

20 with the conductivity of adsorbed imidazole in $\mathbf{1}$ and 2 . The ${ }^{2} \mathrm{H}$ NMR powder line shapes are sensitive

21 to local molecular motion and are characterized in terms of both the time scale and the mode of the

22 motion, such as rotation or wobbling behavior. ${ }^{46,47}$ We introduced imidazole- $d_{4}$ for each host instead of

23 nondeuterated imidazole and checked that the adsorbed amount for each guest was identical to that in

24 the normal hosts. The ${ }^{2} \mathrm{H}$ NMR spectra of $\mathbf{1} \supset \mathrm{Im}$ and $2 \supset \mathrm{Im}$ recorded at different temperatures are shown

25 in Figure 6. In the case of $2 \supset \mathrm{Im}$ (Figure 6b), at the lowest measured temperature of $20{ }^{\circ} \mathrm{C}$, we observed 
1 a clear Pake-type doublet pattern with a splitting width of $120 \mathrm{kHz}$, indicating that the adsorbed

2 imidazole- $d_{4}$ behaves totally anisotropically. As the temperature increases, a narrow Lorentzian-type

3 peak appears in the middle of the anisotropic powder pattern, corresponding to the emergence of

4 isotropic imidazole by thermal activation. There are two possible explanations for the spectrum: the first

5 is that free motional imidazole with low frequency shows a narrow peak and the second is the

6 simultaneous coexistence of frequencies of slow and fast imidazole. Nonetheless, the spectrum at $40{ }^{\circ} \mathrm{C}$

7 indicates the existence of activated guests in pores, and the relative intensity of the activated species

8 increases as the temperature increases to $80^{\circ} \mathrm{C}$.

$9 \quad$ In the case of $\mathbf{1} \supset \mathrm{Im}$, spectra also show doublet powder patterns at low temperatures $(-20$ and -60

$10{ }^{\circ} \mathrm{C}$ ) with the same splitting width as in $2 \supset \mathrm{Im}$ at temperatures lower than $30{ }^{\circ} \mathrm{C}$. However, a narrow

11 Lorentzian-type peak starts to appear at $20^{\circ} \mathrm{C}$. This clearly indicates that at ambient temperature the

12 imidazole in $\mathbf{1}$ can show isotropic motion with a larger frequency than 2 . The fraction of isotropic

13 imidazole becomes dominant at $40{ }^{\circ} \mathrm{C}$, and at $80{ }^{\circ} \mathrm{C}$ we can no longer observe any Pake-doublet pattern

14 at all. This suggests that all adsorbed imidazole within the pores of $\mathbf{1}$ has a fast isotropic motion. Using

15 the NMR line shapes obtained, we evaluated the motion of the imidazole using a simulation procedure.

16 We used a free rotation model of imidazole molecules with tetrahedral orientations as the main motion

17 because this is associated with the Grotthus mechanism. We succeeded in obtaining theoretical patterns

18 for both samples, at each temperature, based on the tetrahedral free rotational model as shown in Figure

19 6, and clearly observed that the rotation frequency of $\mathbf{1}$ is greater than that of $\mathbf{2}$. For example, the

20 frequency of $\mathbf{1}$ at $60{ }^{\circ} \mathrm{C}$ is $45 \mathrm{kHz}$ whereas that of $\mathbf{2}$ shows $10 \mathrm{kHz}$, while the frequency of $\mathbf{1}$ at $20{ }^{\circ} \mathrm{C}(20$

$21 \mathrm{kHz})$ is still larger than that of 2 at $90{ }^{\circ} \mathrm{C}(18 \mathrm{kHz})$ (see Figure S2). Consequently, we are able to conclude that the degree of motional behavior of the accommodated imidazole of $\mathbf{1}$ is greater than in the

23 case of $\mathbf{2}$, which strongly supports the difference in conductivity.

24 We have presented a new approach to create proton transportation space based on the use of proton 25 carrier organic molecules to enhance the proton conductivity of solid materials under anhydrous 
1 conditions at high temperature. The different values of conductivity of imidazole in compounds $\mathbf{1}$ and $\mathbf{2}$

2 are consistent with the dynamic properties of imidazole adsorbed in the pores. The hydrophilic

3 microporous surface of 2 results in strong interaction with even the half amount the adsorbed imidazoles

4 and significantly decelerates their mobility, resulting in a poor proton transfer rate. On the other hand,

5 because of the hydrophobic and flat pore surface of $\mathbf{1}$, adsorbed imidazole can move more freely than in

62 and than bulk phase, and we eventually observe higher proton conductivity, which is comparable to

7 that of a conventional organic polymer conductor such as poly(4-vinylimidazole). ${ }^{48}$ PCP can provide an

8 appropriate pore environment and size for target proton carrier by the fine-tuning of their components.

9 In the other word, the optimum mobility and density of proton carriers can be reached by taking

10 advantage of the designability of PCPs. The strategy would be considered significant to prepare hybrid

11 materials high proton-conductive.

\section{Experimental section}

\section{Materials}

Aluminium(III) nitrate nanohydrate $\mathrm{Al}\left(\mathrm{NO}_{3}\right)_{3} \cdot 9 \mathrm{H}_{2} \mathrm{O}$ (WAKO, 99.9\%); terephthalic acid $\mathrm{HO}_{2} \mathrm{C}-\left(\mathrm{C}_{6} \mathrm{H}_{4}\right)-\mathrm{CO}_{2} \mathrm{H}$ (WAKO, 95\%); 1,4-naphthalene dicarboxylic acid $\mathrm{HO}_{2} \mathrm{C}-\left(\mathrm{C}_{10} \mathrm{H}_{8}\right)-\mathrm{CO}_{2} \mathrm{H}$ (WAKO, 95\%); imidazole (WAKO, 99\%) and imidazole (D-4, CIL, 98\%) were used as received. Distilled water was used.

\section{Synthesis of $\left\{\mathrm{Al}\left(\mu_{2}-\mathrm{OH}\right)(1,4-n d c)\right\}_{n}(1)$}

A mixture of $\mathrm{Al}\left(\mathrm{NO}_{3}\right)_{3} \cdot 9 \mathrm{H}_{2} \mathrm{O}(0.375 \mathrm{~g}, 1.0 \mathrm{mmol})$; 1,4-naphthalene dicarboxylic acid (0.108 g, 0.5 mmol) and deionized water $(10 \mathrm{~mL})$ was placed in a $23 \mathrm{~mL}$ Teflon autoclave and heated at $180{ }^{\circ} \mathrm{C}$ for

21 one day. The initial $\mathrm{pH}$ of the reaction mixture was 2.5 and the final $\mathrm{pH}$ was 2.0. After filtering and washing the crude product with distilled water, a pure, light-yellow powder of $\mathbf{1} \cdot 2 \mathrm{H}_{2} \mathrm{O}$ was obtained

23 (yield 80\%). The sample was evacuated at $150{ }^{\circ} \mathrm{C}$ for 12 hours to afford the guest-free compound 1.

\section{Synthesis of $\left\{\mathrm{Al}\left(\boldsymbol{\mu}_{2}-\mathrm{OH}\right)(1,4-b d c)\right\}_{n}(2)$}


1 The synthesis of 2 was carried out under hydrothermal conditions using $\mathrm{Al}\left(\mathrm{NO}_{3}\right)_{3} \cdot 9 \mathrm{H}_{2} \mathrm{O}(1.30 \mathrm{~g}, 3.5$

2 mmol); 1,4-benzenedicarboxylic acid $(0.288 \mathrm{~g}, 2.5 \mathrm{mmol})$ and distilled water $(10 \mathrm{~mL})$. The reaction was

3 performed in a $23 \mathrm{~mL}$ Teflon autoclave. The reaction mixture was heated at $220^{\circ} \mathrm{C}$ for three days. After

4 filtering and washing with distilled water, a white powder was obtained. It was identified by powder

5 X-ray diffraction analysis. The excess terephthalic acid in the pores was removed by high-temperature

6 treatment at $330{ }^{\circ} \mathrm{C}$ for three days. X-ray powder diffraction (XRPD) analysis revealed that the material

7 was the guest-free compound 2.

\section{Preparation of imidazole-loaded frameworks}

$9 \quad$ Products 1 and 2 were again degassed by heating to $120{ }^{\circ} \mathrm{C}$ under reduced pressure for $12 \mathrm{~h}$ to 10 remove guest molecules. Imidazole was vaporized into guest-free $\mathbf{1}$ and $\mathbf{2}$ at $120{ }^{\circ} \mathrm{C}$, overnight, to yield

11 1 $\supset$ Imi and $2 \supset$ Imi. XRPD patterns of both these compounds confirmed that the frameworks were maintained. The amount of loaded imidazole was determined by TG analysis.

\section{Proton conductivity measurement of $1 \supset \mathrm{Im}$ and $2 \mathrm{Im}$}

Samples for conductivity measurements were prepared by sandwiching the respective powders

1 $\supset$ Im and 2つIm between two gold-coating electrodes (diameter $3 \mathrm{~mm}$ ) and then tightly connecting the two electrodes, by means of springs, to ensure good contact between the sample and each electrode. Temperature-dependent conductivities of $\mathbf{1} \supset \mathrm{Im}$ and $2 \supset \mathrm{Im}$ were determined using alternative current (AC) impedance spectroscopy (Solartron SI 1260 Impedance/Gain-Phase analyzer), using a homemade cell over the frequency range $1 \mathrm{~Hz}-10 \mathrm{MHz}$ and with an input voltage amplitude of $100 \mathrm{mV}$. The measurement cell was filled with nitrogen at atmospheric pressure prior to recording the measurements. ZView software was utilized to extrapolate impedance data results via equivalent circuit simulation to complete the Nyquist plot and obtain the resistance values.

\section{${ }^{2}$ H solid-state NMR}


1 Solid-state ${ }^{2} \mathrm{H}$ NMR spectra were recorded using a Varian Chemagnetics CMX-300 spectrometer, at $245.826 \mathrm{MHz}$, and a quadrupole echo pulse sequence. Simulated spectra were produced with FORTRAN 3 programs written by us.

4 


\section{FIGURE CAPTIONS}

2

(a)

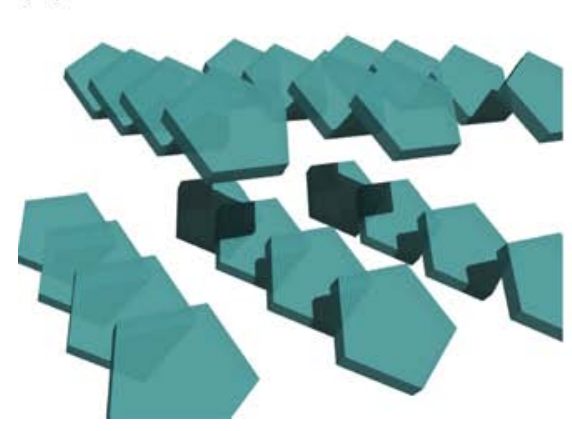

(b)

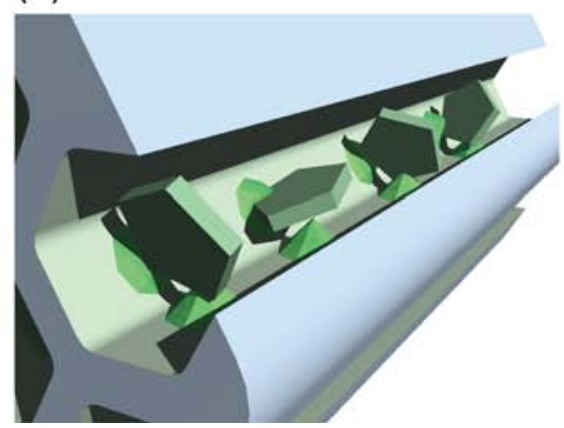

(c)

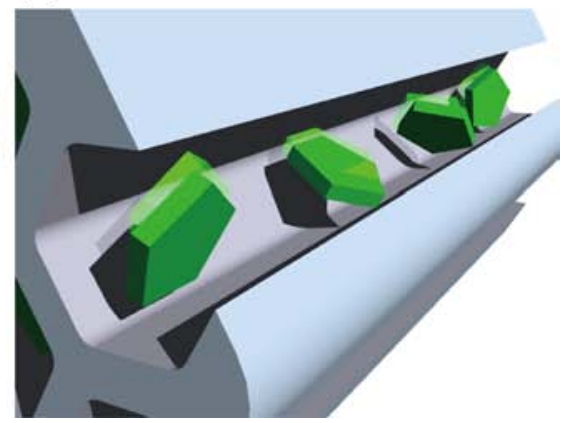

Figure 1. Imidazole molecules are densely packed with low mobility that adversely affects proton transport process. This occurs in the bulk solid (a). Imidazole accommodated in nanochannel containing the active site with a high affinity to imidazole. The strong host-guest interaction retards the mobility of imidazole to afford the low proton conductivity (b). Imidazoles are accommodated in nanochannel without strong host-guest interaction, and therefore, the molecules obtain the high mobility to show high proton conductivity (c). 


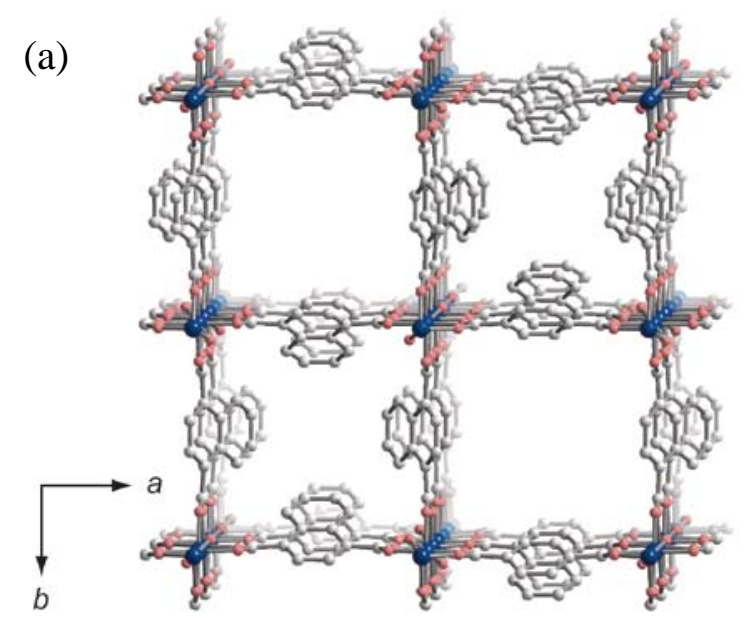

(b)
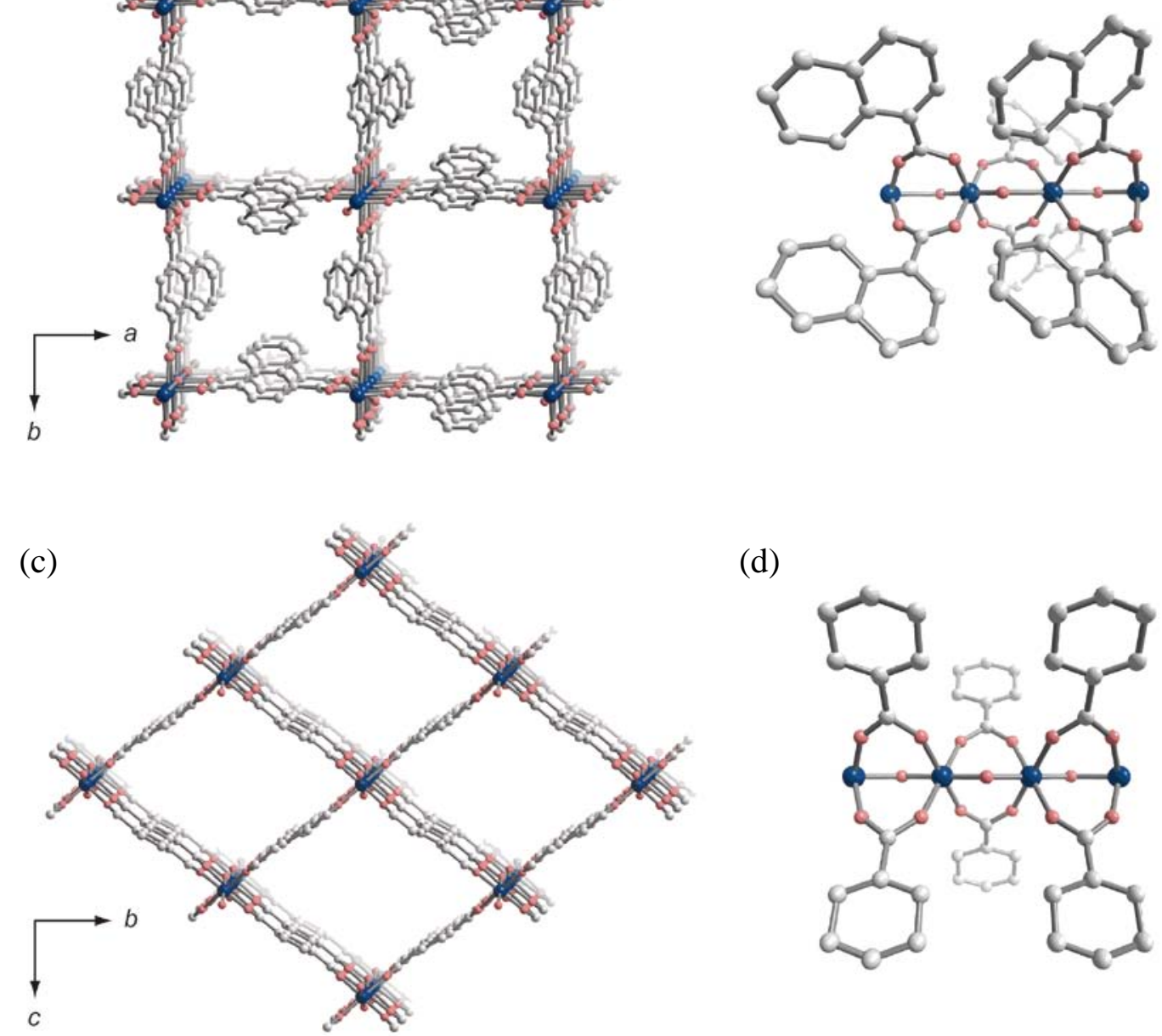

(d)

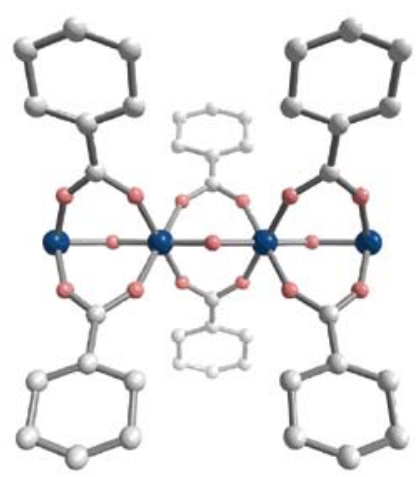

Figure 2. 3D structures of $\mathbf{1}$ (a) and 2 (c). Al, C, and $\mathrm{O}$ are represented in blue, gray, and red, respectively. $\mathrm{H}$ atoms are omitted for clarification. (b) and (d) show comparison of ligand size effect on $\mu_{2}-\mathrm{OH}$ group of $\mathbf{1}$ and 2 respectively. 


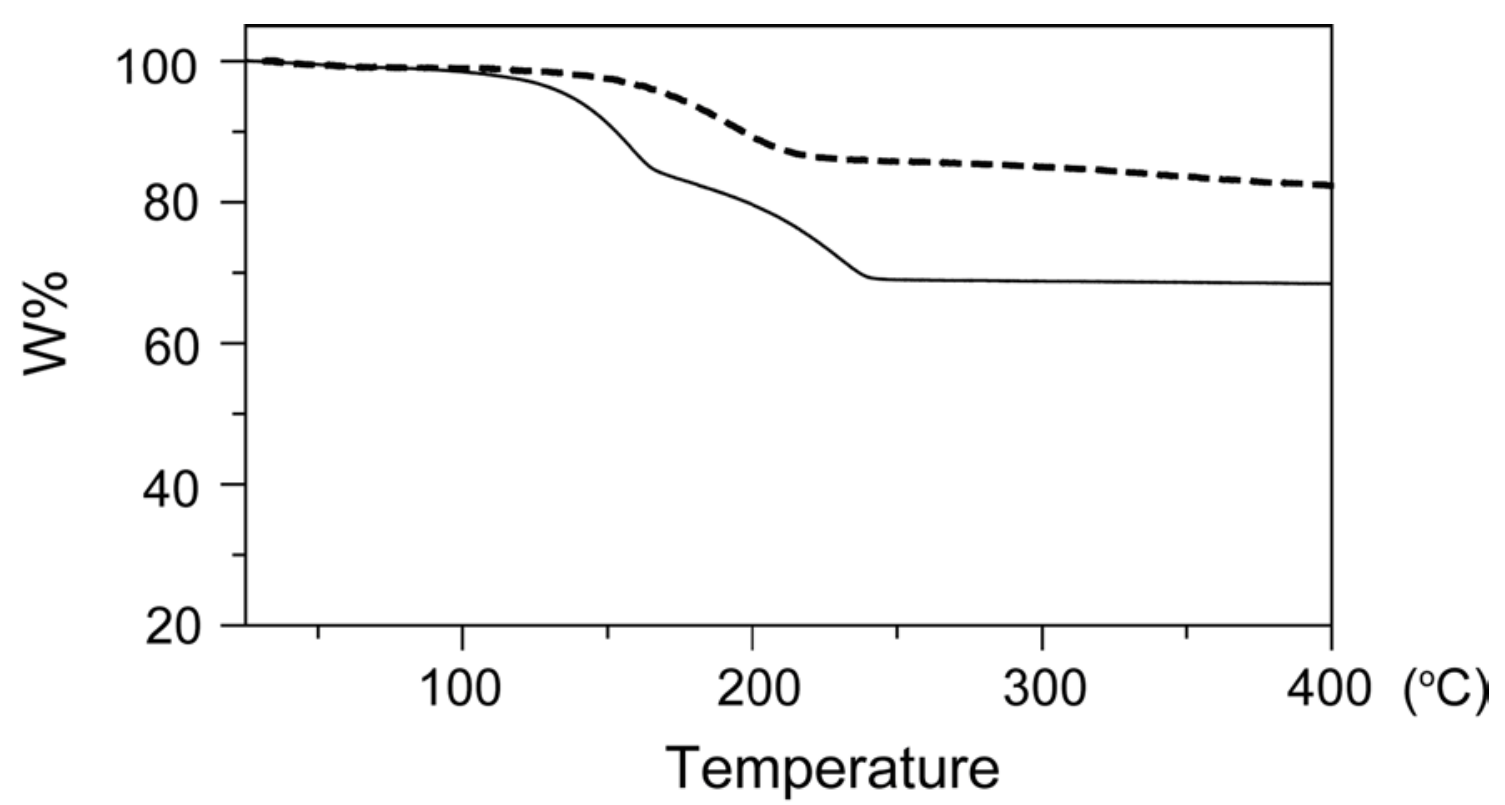

Figure 3. TGA curves for $1 \supset \mathrm{Im}$ (dash line) and $2 \supset \mathrm{Im}$ (solid line) over the temperature range from 25 - $400{ }^{\circ} \mathrm{C}$ at heating rate $10{ }^{\circ} \mathrm{C} \min ^{-1}$ under $\mathrm{N}_{2}$ atmosphere. The guest release of $\mathbf{1} \supset \mathrm{Im}$ occurs in one single step that clues the homogeneous installation of imidazole in 1, whereas of $\mathbf{2} \supset$ Im occurs in two steps, indicating two types of imidazole (strongly and weakly interacts with 2). 

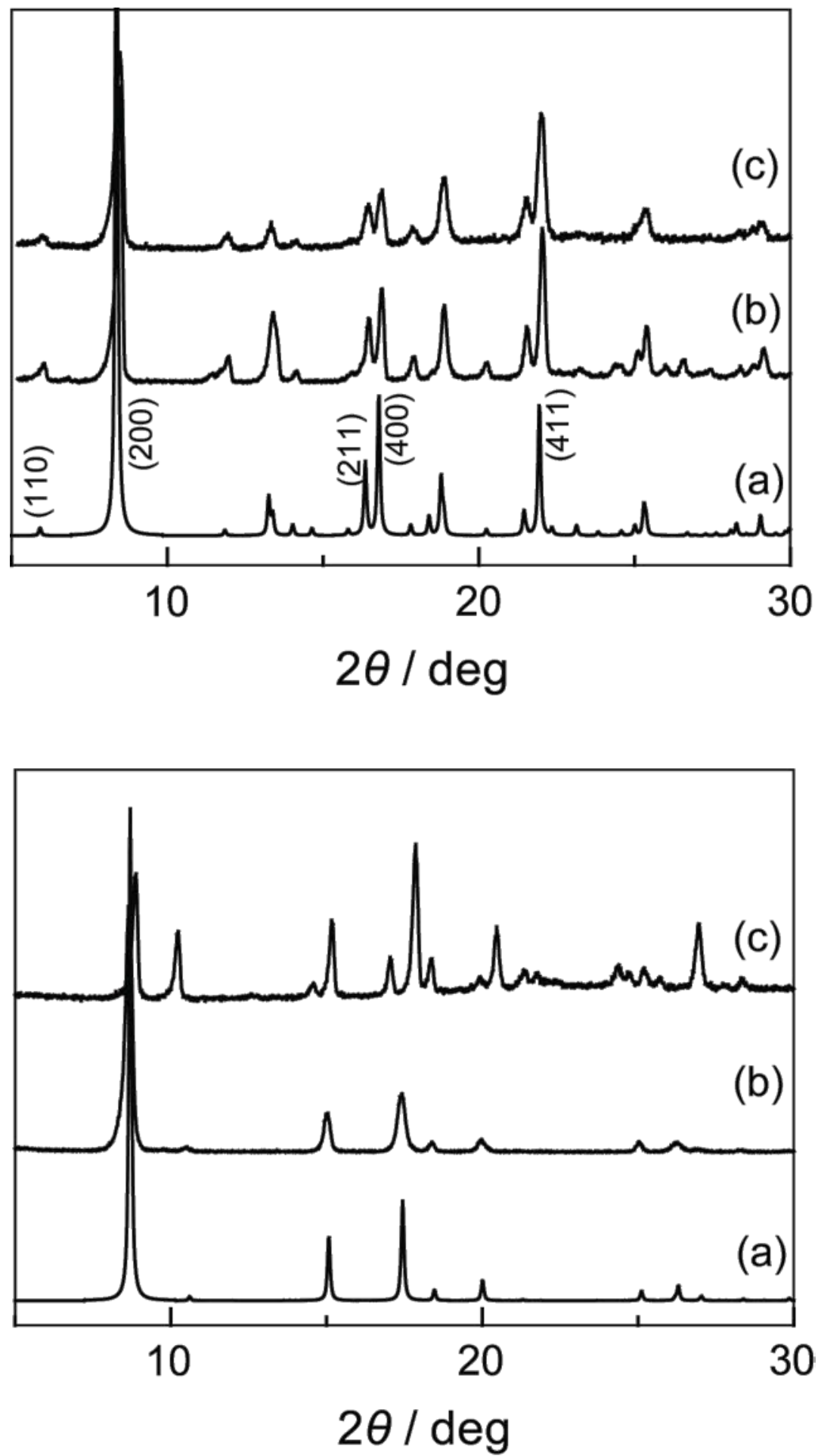

Figure 4. Above: XRPD patterns of simulated $\mathbf{1} \cdot 2 \mathrm{H}_{2} \mathrm{O}$ (a), $\mathbf{1}$ (b), and $\mathbf{1} \supset \mathrm{Im}$ (c). The patterns before and after accommodation of imidazole are identical. Below: XRPD patterns of simulated 2 (a), 2 (b), and 2つIm (c). A change in XRPD patterns after accommodation of imidazole is observed. ${ }^{39}$ 

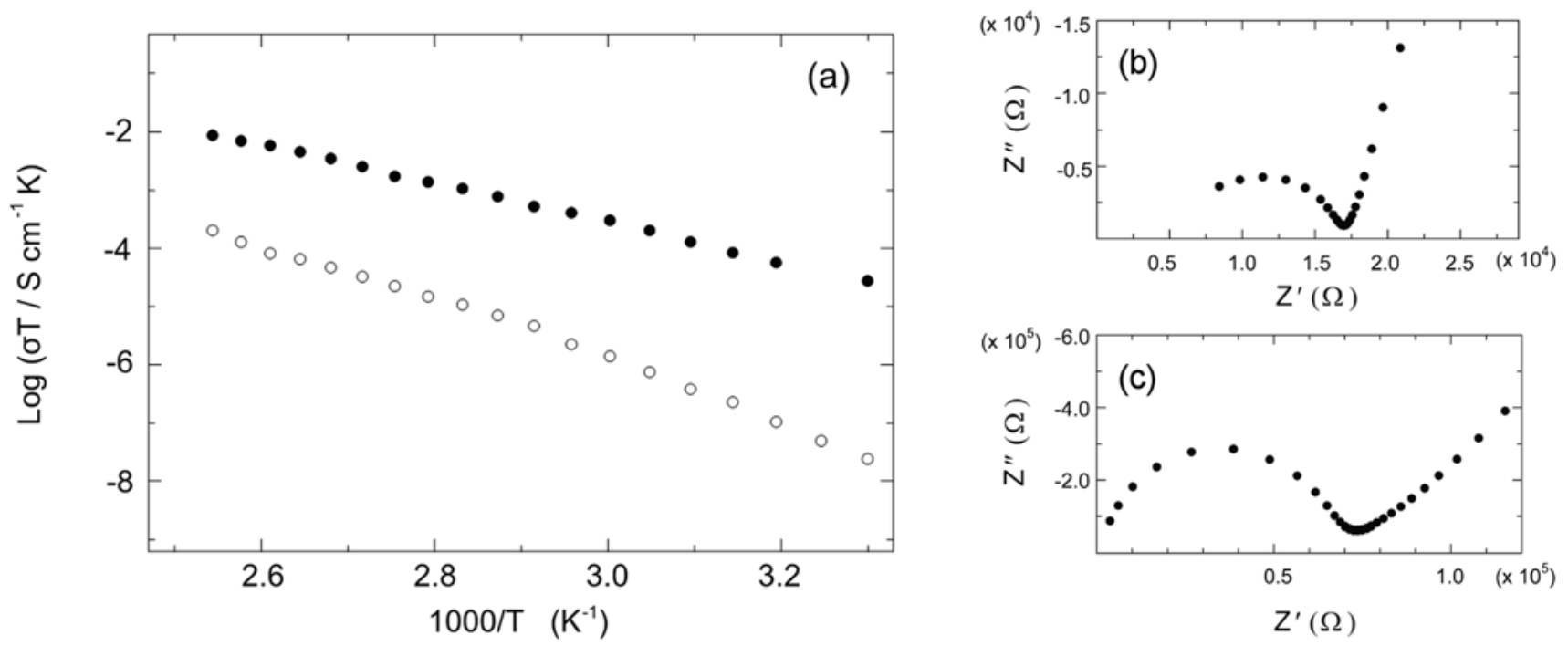

Figure 5. (a) Proton conductivity of $1 \supset \mathrm{Im}$ (filled dots) and 2つIm (empty dots) under anhydrous 1 condition performed by A.C. impedance analyzer. Nyquist diagrams of $\mathbf{1} \supset \operatorname{Im}$ (b) and $2 \supset \operatorname{Im}($ c) at 

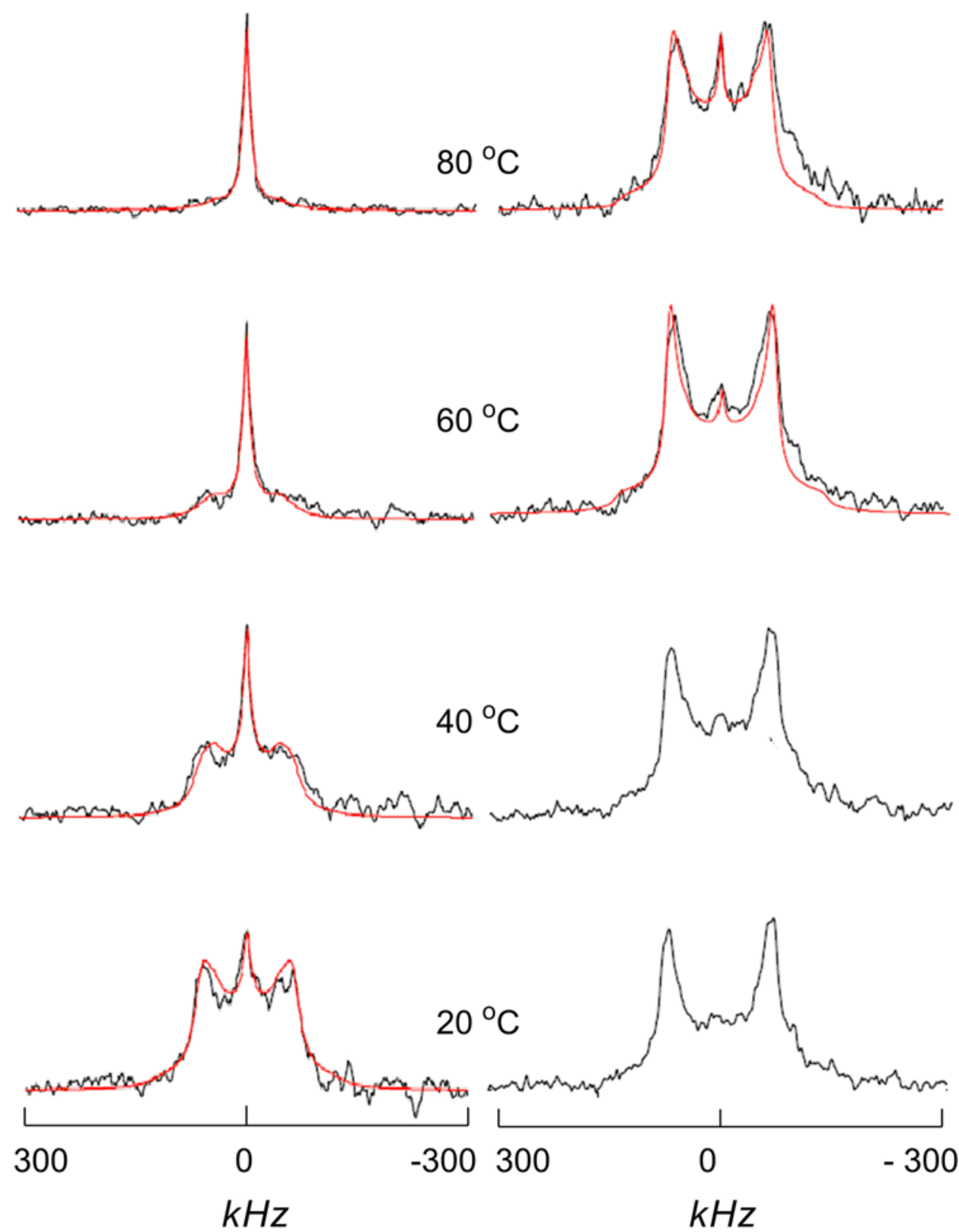

Figure 6. ${ }^{2} \mathrm{H}$ solid-state NMR spectra of $1 \supset \mathrm{Im}-d_{4}$ (left) and $2 \supset \mathrm{Im}-d_{4}$ (right). The simulation results are shown in red lines. 


\section{References:}

21 Kreuer, K. D., Paddison, S. J., Spohr, E. and Schuster, M., Transport in Proton Conductors for

Fuel-Cell Applications: Simulations, Elementary Reactions, and Phenomenology. Chem. Rev. 104 (10), 4637 (2004).

Martin F.H. Schuster and Meyer, W. H., Anhydrous Proton-Conducting Polymers. Annu. Rev. Mater. Res. 33, 233 (2003).

Jannasch, P., Recent developments in high-temperature proton conducting polymer electrolyte membranes. Curr. Opin. Colloid Interface Sci. 8 (1), 96 (2003). membranes. Electrochim. Acta 51 (7), 1351 (2006).

West, A. R., Basic Solid State Chemistry. (Wiley, 1999).

Kawada, A., McGhie, A. R. and Labes, M. M., Protonic Conductivity in Imidazole Single Crystal. J. Chem. Phys. 52 (6), 3121 (1970).

7 Noro, S., Kitagawa, S., Kondo, M. and Seki, K., A New, Methane Adsorbent, Porous Coordination Polymer. Angew. Chem. Int. Ed. 39 (12), 2081 (2000).

Rowsell, J. L. and Yaghi, O. M., Strategies for hydrogen storage in metal-organic frameworks. Angew. Chem. Int. Ed. 44 (30), 4670 (2005).

Ferey, G.et al., Hydrogen adsorption in the nanoporous metal-benzenedicarboxylate $\mathrm{M}(\mathrm{OH})(\mathrm{O} 2 \mathrm{C}-\mathrm{C} 6 \mathrm{H} 4-\mathrm{CO} 2)(\mathrm{M}=\mathrm{Al3}+, \mathrm{Cr} 3+)$, MIL-53. Chem. Commun. (24), 2976 (2003). (5622), 1127 (2003).

Li, H., Eddaoudi, M., O'Keeffe, M. and Yaghi, O. M., Design and synthesis of an exceptionally stable and highly porous metal-organic framework. Nature 402 (6759), 276 (1999). Coordination Polymers: Removal of Organosulfur Compounds. J. Am. Chem. Soc. 130 (22), 6938 (2008).

13 Finsy, V.et al., Pore-Filling-Dependent Selectivity Effects in the Vapor-Phase Separation of Xylene Isomers on the Metal-Organic Framework MIL-47. J. Am. Chem. Soc. 130 (22), 7110 (2008).

14 Bradshaw, D.et al., Permanent Microporosity and Enantioselective Sorption in a Chiral Open Framework. J. Am. Chem. Soc. 126 (19), 6106 (2004).

15 Dybtsev, D. N.et al., Microporous Manganese Formate: A Simple Metal-Organic Porous Material with High Framework Stability and Highly Selective Gas Sorption Properties. J. Am. Chem. Soc. 126 (1), 32 (2004). 
116 Min, K. S. and Suh, M. P., Self-Assembly and Selective Guest Binding of Three-Dimensional Open-Framework Solids from a Macrocyclic Complex as a Trifunctional Metal Building Block.

Chem. Eur. J. 7 (1), 303 (2001).

Wang, B.et al., Colossal cages in zeolitic imidazolate frameworks as selective carbon dioxide reservoirs. Nature 453 (7192), 207 (2008).

Hasegawa, S.et al., Three-Dimensional Porous Coordination Polymer Functionalized with Amide Groups Based on Tridentate Ligand: Selective Sorption and Catalysis. J. Am. Chem. Soc. 129 (9), 2607 (2007).

Horike, S., Dinca, M., Tamaki, K. and Long, J. R., Size-Selective Lewis Acid Catalysis in a Microporous Metal-Organic Framework with Exposed Mn2+ Coordination Sites. J. Am. Chem. Soc. 130 (18), 5854 (2008).

Cho, S.-H.et al., A metal-organic framework material that functions as an enantioselective catalyst for olefin epoxidation. Chem. Commun. (24), 2563 (2006). with large pores. Chem. Commun. (27), 2820 (2007).

Schroder, F.et al., Ruthenium Nanoparticles inside Porous [Zn4O(bdc)3] by Hydrogenolysis of Adsorbed [Ru(cod)(cot)]: A Solid-State Reference System for Surfactant-Stabilized Ruthenium Colloids. J. Am. Chem. Soc. 130 (19), 6119 (2008).

Ingleson, M. J.et al., Generation of a solid Bronsted acid site in a chiral framework. Chem. Commun. (11), 1287 (2008).

Fujita, M., Kwon, Y. J., Washizu, S. and Ogura, K., Preparation, Clathration Ability, and Catalysis of a Two-Dimensional Square Network Material Composed of Cadmium(II) and 4,4'-Bipyridine. J. Am. Chem. Soc. 116 (3), 1151 (1994).

Seo, J. S.et al., A homochiral metal-organic porous material for enantioselective separation and catalysis. Nature 404 (6781), 982 (2000).

Evans, O. R., Ngo, H. L. and Lin, W., Chiral Porous Solids Based on Lamellar Lanthanide Phosphonates. J. Am. Chem. Soc. 123 (42), 10395 (2001).

Ferey, G.et al., Mixed-Valence Li/Fe-Based Metal-Organic Frameworks with Both Reversible Redox and Sorption Properties. Angew. Chem. Int. Ed. 46 (18), 3259 (2007).

Kitagawa, H.et al., Highly proton-conductive copper coordination polymer, H2dtoaCu (H2dtoa=dithiooxamide anion) Inorg. Chem. Commun. 6 (4), 346 (2003).

29 Yamada, T., Sadakiyo, M. and Kitagawa, H., High Proton Conductivity of One-Dimensional Ferrous Oxalate Dihydrate. J. Am. Chem. Soc. 131 (9), 3144 (2009). 
$130 \quad$ Uemura, T.et al., Radical polymerisation of styrene in porous coordination polymers. Chem. Commun. (48), 5968 (2005).

Uemura, T.et al., Conformation and Molecular Dynamics of Single Polystyrene Chain Confined in Coordination Nanospace. J. Am. Chem. Soc. 130 (21), 6781 (2008).

Mulfort, K. L. and Hupp, J. T., Chemical Reduction of Metal-Organic Framework Materials as a Method to Enhance Gas Uptake and Binding. J. Am. Chem. Soc. 129 (31), 9604 (2007).

Muller, M.et al., Loading of MOF-5 with $\mathrm{Cu}$ and $\mathrm{ZnO}$ nanoparticles by gas-phase infiltration with organometallic precursors: Properties of $\mathrm{Cu} / \mathrm{ZnO} @$ MOF-5 as catalyst for methanol synthesis. Chem. Mater. 20 (14), 4576 (2008).

Turner, S.et al., Direct Imaging of Loaded Metal-Organic Framework Materials (Metal@MOF-5).Chem. Mater. 20 (17), 5622 (2008).

Horcajada, P.et al., Flexible Porous Metal-Organic Frameworks for a Controlled Drug Delivery. J. Am. Chem. Soc. 130 (21), 6774 (2008).

Horcajada, P.et al., Metal-Organic Frameworks as Efficient Materials for Drug Delivery. Angew. Chem. Int. Ed. 45 (36), 5974 (2006).

Tanaka, D.et al., Anthracene array-type porous coordination polymer with host-guest charge transfer interactions in excited states. Chem. Commun. (30), 3142 (2007).

Comotti, A.et al., Nanochannels of Two Distinct Cross-Sections in a Porous Al-Based Coordination Polymer. J. Am. Chem. Soc. (2008).

Loiseau, T.et al., A Rationale for the Large Breathing of the Porous Aluminum Terephthalate (MIL-53) Upon Hydration. Chem. Eur. J. 10 (6), 1373 (2004).

Serre, C.et al., An Explanation for the Very Large Breathing Effect of a Metal-Organic Framework during CO2 Adsorption. Adv. Mater. 19 (17), 2246 (2007).

Spek, A. L., Foundations of Crystallography. Acta Crystallogr., Sect. A A46, c34 (1990).

Craven, B. M., McMullan, R. K., Bell, J. D. and Freeman, H. C., The crystal structure of imidazole by neutron diffraction at 20 oCand -150 oC. Acta Crystallogr., Sect. B 33 (8), 2585 (1977).

Horike, S.et al., Motion of methanol adsorbed in porous coordination polymer with paramagnetic metal ions. Chem. Commun. (19), 2152 (2004).

Ueda, T.et al., Phase transition and molecular motion of cyclohexane confined in metal-organic framework, IRMOF-1, as studied by 2H NMR. Chem. Phys. Lett. 443 (4-6), 293 (2007).

Horike, S.et al., Dynamic Motion of Building Blocks in Porous Coordination Polymers13. Angew. Chem. Int. Ed. 45 (43), 7226 (2006). 
146 Schmidt-Rohr, K. and Spiess, H. W., Multidimensional Solid-State NMR and Polymers.

$2 \quad$ (Academic Press, London, 1994).

$3 \quad 47$ Abragam, A., Principles of Nuclear Magnetism (Oxford University Press, Oxford, 1961).

448 Bozkurt, A. and Meyer, W. H., Proton conducting blends of poly(4-vinylimidazole) with 5 phosphoricacid. Solid State Ionics 138, 259 (2001). 